\title{
La realidad a prueba de lo virtual
}

\author{
Reality challenged by the virtual world
}

\begin{abstract}
Rodrigo Leiva $\mathrm{B}^{2}$
hrodriclb@gmail.com

\section{Resumen}

Entrados en la era de la revolución digital, la humanidad -lo mismo que las formas estructurales en que se han sostenido los intercambios sociales a lo largo de la historia- experimentan el día de hoy una trasformación que bien podríamos llamar "heterogénesis", tan radical que amenaza con subvertir los supuestos del orden más natural: el cuerpo, la identidad sexual, la certeza de morir o enfermar e incluso el mismo sentido de realidad, los cuales empiezan a difuminar sus fundamentos en lo psíquico. El hombre se ha arrancado la piel de su especie para encontrar en lo virtual, en el reflejo de las pantallas, su nueva condición -imaginaria- de "superhombre" libre de las ataduras de lo real, pero embebido por el placer alucinógeno de una realidad de fantasía en la que está cautivo. ¿Qué consecuencias trae pues el impacto desmedido de las realidades de síntesis en el psiquismo humano?
\end{abstract}

\section{Palabras claves}

Heterogénesis, principio de placer, principio de realidad, realidad efectiva, cyborg, lo virtual, lo digital.

\begin{abstract}
Nowadays, when we have entered into the age of the digital revolution, humanity-same as the structural forms in which social exchanges have been maintained all through history-head toward a radical transformation that we could name "heterogenesis", which menaces in subverting the basic mental conditions of all natural order: body, sexual identity, death, and sickness certainty, even reality itself as never after is beginning to dissolve it's basis in the psychical dimension. Humanity has pull out its own species skin in order to find in the virtual, in the screens bright, its new identity-imaginary-as "superman", free from the ties of what is real but absorbed by the hallucinogenic pleasure of a fake reality from which we are prisoners. Which are the consequences that a disproportionate impact with synthetic realities brings to the mental health of humans?
\end{abstract}

\section{Keywords}

Heterogenesis, pleasure principle, principle of reality, effective reality, cyborg, virtual, digital.

Forma sugerida de citar: LEIVA B., RODRIGO (2013). "La realidad a prueba de lo virtual”. En: Universitas, XI (19), julio-diciembre, p. 147-180. Quito: Editorial Abya Yala/Universidad Politécnica Salesiana.

2 Psicólogo clínico de la Pontificia Universidad Católica del Ecuador. 


\section{Construcción de la identidad, el devenir de un $\mathrm{Yo}^{3}$}

"Cuando a través de la pantalla nos adentramos en las comunidades virtuales, reconstruimos nuestras identidades al otro lado del espejo" (Turkle, 1995: 125). Según nos lo indica la teoría psicoanalítica, el Yo del sujeto se construye en un continuo devenir como un conjunto de identificaciones nacientes de toda interacción humana. Podemos determinar el momento en que este surgimiento toma lugar como el instante en que emerge la figura "yoica" del vasto océano del reino objetual en el que anterior a este desarrollo aún se confundía, "en ese tiempo el yo-sujeto coincide con lo placentero, y el mundo exterior, con lo indiferente (y eventualmente, en cuanto fuente de estímulos, con lo displacentero)" (Freud, 1915: 129-130).

Por otro lado, la relación al "otro" del semejante es una condición sine qua non para el advenimiento de este Yo, en cuanto instancia diferenciada del universo de objetos circundantes de su entorno. Si esta relación dialéctica con la alteridad, de semblanza y diferencia, que pone distancia a la vez que introyecta a lo ajeno, es impedida - un ejemplo de ello son los casos de "hospitalismo" descritos por René Spitz-, entonces la formación de la instancia yoica sufrirá graves lesiones. La célebre frase del poeta francés Rimbaud: Je est un autre, "yo es otro" adquiere aquí todo su alcance. El Yo es siempre un alter-ego, un otro a partir del cual emerge este como formación subjetiva diferenciada de la de sus semejantes. Y Lacan nos recuerda: "el yo es desde el inicio por sí mismo otro, porque se instaura en una dualidad interna al sujeto" (Lacan, 1949: 125).

Ahora bien, ¿de qué modo los procesos de heterogeneización de lo virtual inciden con su impacto en la construcción de la identidad de los sujetos?

3 En adelante, será importante diferenciar el uso que daremos a dos términos centrales en nuestra articulación, a saber, "lo real" y "realidad". Por un lado, la dificultad de conceptualizar a "lo real" está en su fundamento, sin embargo, diremos que en el psicoanálisis lacaniano, lo real determina justamente aquello que escapa a toda posibilidad de representación. Lo real como "la Cosa” (Das Ding) en sí misma, en tanto que inaprehensible e inasible, imposible de ser pensada y por lo tanto no hay manera que el lenguaje pueda dar cuenta de su experiencia. Lo real se ubica en oposición a lo imaginario y simbólico de los registros del sujeto. Por otro lado, la "realidad" es definida en relación inmanente con el sistema de percepciones del sujeto, por tanto, estrechamente ligada a la consciencia. Es la imagen sensible -el facsímil- de lo que se ubica en el exterior de sí mismo y de lo que el sujeto puede dar cuenta, es decir, lo real mediado por lo imaginario y lo simbólico. En consecuencia, la realidad aparece moldeada por cada sujeto como por su inconsciente; esto es, en términos de Freud, realidad "psíquica". 
Escuchemos los siguientes testimonios de jóvenes usuarios de comunidades virtuales como los MUD (Munti-Users Domain), recogidos por la doctora en psicología clínica, Sherry Turkle, en su libro La vida en las pantallas:

Puedes ser quien quieras ser. Te puedes definir completamente a ti mismo si quieres. Puedes ser del sexo opuesto. Puedes ser más extrovertido. Puedes ser menos extrovertido. Lo que sea. Puedes ser simplemente quien quieras, realmente, quien tengas capacidad de ser. No tienes que preocuparte mucho por los estereotipos que las otras personas te colocan. Es fácil cambiar la forma en que la gente te percibe porque todo lo que tienen es lo que tú les muestras (Turkle, 1995: 234).

El encanto con lo virtual reside en asumir como certeza la imaginaria posibilidad de transformarnos según sea la orden de nuestros deseos. La "omnipotencia de las ideas" -atributo narcisista del idealich- reverbera aquí con fuerza delirante. Es la factibilidad ilusoria de (re)crearnos virtualmente según la medida de los ideales (los más locos, los más descentrados, los menos reales); pero además, sirve para el resarcimiento narcisista como compensación de las frustraciones que recibimos inevitablemente de la realidad y que el Yo en su materia encarna. Adquirimos conciencia de una realidad justamente por efecto de las insatisfacciones que esta nos provoca. De ahí que no sorprende el efecto adictivo con que estos mundos estupefacientes se comercializan, para quienes la identificación de su propia imagen -imagen especular fundante del Yo, teorizada por Lacan en sus escritos a propósito del "estadio del espejo"- no opera otro efecto que el de una repulsión. Hay pues que reinventar la realidad y con ello a nosotros mismos.

Existen medidas que tomar al respecto. Precavernos sobre todo en etapas de la vida psíquica en donde la instancia yoica apenas está adquiriendo la forma definitiva, a saber, en la infancia y la adolescencia, cuando los torbellinos de la pulsión buscan desesperados el apuntalamiento de un Yo plenamente constituido bajo un nuevo orden de identificaciones.

Por ejemplo, respecto al "Estadio del espejo" época que se sitúa alrededor de los 6-18 primeros meses de vida del sujeto, en la cual se trazan los primeros esbozos de un Yo, Lacan enseña lo siguiente: "basta comprenderlo cómo [...] una identificación en el sentido pleno que el análisis da a este término: a saber, 
la transformación producida en el sujeto cuando asume una imagen" (Lacan, 1949: 87). Es una imagen especular que manifiesta "la matriz simbólica en la que el yo se precipita en una forma primordial, antes de objetivarse en la dialéctica de la identificación con el otro y antes de que el lenguaje le restituya en lo universal su función de sujeto" (Lacan, 1949: 87). ¿Es entonces a nivel de lo imaginario dónde los procesos de identificación toman lugar?

Veamos. Del otro lado de las pantallas encontramos un mundo de pura imagen, un trasunto de realidad simulada, recreada a partir de códigos binarios que cifran su programación específica y que carecen por completo de solidez y sustancia. Nada en concreto hay detrás de ellas e incluso su estructura lógicomatemática con que su ingeniería la compone se halla a distancia de la aprehensión de sus usuarios.

Una realidad en potencia (virtualis) con la que preferimos relacionarnos es "lo virtual". Espacio imaginario, pantalla funcionando como espejo que, sin dar aviso de ello, paradojalmente abre un abismo en la interacción humana hacia lo que se conoce como "telepresencia". La comunicación in vivo, en adelante, se vuelve casi insostenible, incluso angustiante, su despliegue no es posible sino a través de un intermediario esencial -la interfaz- que vehiculiza a la vez que desvía palabra y deseo en una imagen de encanto que coloca nuestra presencia a distancia de una genuina comunicación. Este intermediario artificial depura todas las imperfecciones de una realidad que es fuente del displacer. Así, el con-tacto y la intimidad, lo mismo que toda la fuerza que concentra una mirada humana reduce su intensidad en el tamiz de lo virtual, como si su naturaleza fuese tan cruda que necesitásemos pixelarla para que su significación se torne más blanda, más manejable, menos angustiante, menos real.

En estos espacios de volátil atmosfera donde nos reinventamos siempre, la comunicación por efecto de un prefijo que tiene muy bien en cuenta la categoría del abismo sobre el que se erige, pasa a ser "tele"-comunicación. Así, nuestros interlocutores virtuales siguen los puntos de referencia en rasgos de personalidad digitalizada, de sus apariencias en realidad simuladas, artificiales. Y en esto consiste el proceso de "heterogeneización" que caracteriza a lo virtual, un proceso a cuya magia no escapa ninguna forma, idea o entidad que atraviese la pantalla. El único vector que orienta lo virtual es su insaciable búsqueda por la 
embriaguez del placer en los espejismos de una alteridad siempre en boceto y además desechable.

En este sentido -replanteando el problema de la identificación-, se corre el riesgo - ciertamente real en sus efectos a nivel del psiquismo- de operar identificaciones virtuales con "personajes simulados" que carecen de todo soporte sustancial... más efímeros que una flor. En este circuito ya no hay una base real dónde construir una identidad que sea continua y coherente en el tiempo. En consecuencia: 'l'enfant s'identifie aux chaînes, aux marques et aux personnages de médias de masse, tend à le priver d'identification primaire"4 (Stiegler y Tisseron, 2009: 84). Lo que fascina de estos espacios es la posibilidad que, con la identificación en lo virtual, se inaugura el ser - sea uno y varios a la vez, que es lo mismo que ser nadie o todos a la vez, pues esto es el "hipercuerpo"- y cuando nos cansamos del personaje que simulamos lo desechamos para vestirnos al paso de otro menos errado y más acorde a nuestros deseos del momento. Se trata de un ámbito muy peligroso para los circuitos del psiquismo pues el proceso de identificación parecería estar siempre desenchufándose de su relación de objeto, a riesgo de provocar un cortocircuito.

Sin embargo, haremos lo justo al destacar el otro lado de este proceso, el cual supone la posibilidad de reincorporar al sujeto al seno de lo social, lo cual no tiene otro sentido que reintegrarlo al intercambio de palabra: "los espacios virtuales pueden proporcionar la seguridad para exponernos a lo que encontramos a faltar para que podamos empezar a aceptarnos como lo que somos" (Turkle, 1995: 239).

Así, lo virtual funciona como "válvula de escape" de algo que es con-nato a la realidad misma, esto es, su insatisfacción; y en el caso de la identidad, de aquella referida al Yo del sujeto. Anteriormente hablábamos de la "resistencia" de la realidad como una de sus propiedades, la cual a la vez que es fuente de frustraciones -pues resiste a toda intención de cambio-, se asegura también como apoyatura del ser en una línea prolongada de tiempo. Así, la realidad coloca "distancia" entre el Yo y los objetos que lo rodean, génesis de la cons-

4 "El niño se identifica con las cadenas, con las marcas y con los personajes de los medios de comunicación en masa, lo que tiende a privarlo de identificación primaria" (traducción del autor). 
ciencia y de la diferenciación entre el mundo interior (subjetivo) y el mundo exterior (objetivo).

Esta distancia no es comparable con la de lo virtual pues esta última se erige siempre sobre la ilusión del "principio de placer" -que conduce al psiquismo a la alucinación de la realidad en tanto que es fantaseada. En cambio, en la dificultad con que lo real del mundo resiste a los procesos de heterogénesis, es compelido el sujeto a un esfuerzo (drang), a la "inversión" de montos de energía psíquica que desencadenen la operación motriz más acorde, a fin de operar cualquier cambio en el campo de la realidad efectiva: esto es el "principio de realidad". El que la realidad se nos resista permite al ser humano tomar conciencia de lo que no forma parte de su totalidad física y psicológica. Aunque su carácter de resistencia le da su connotación de realidad dolorosa e insatisfaciente, no obstante solo en la medida en que logramos reconocerlo podemos transformarla en fuente de satisfacciones que, siguiendo la orden del principio de realidad, difieren el placer inmediato a otro que sin duda estará más asegurado en un tiempo futuro.

La realidad se nos resiste, decíamos, pero no así los mundos virtuales ya que son producción humana que se generan a partir de nuestros deseos. Cuando nos acercamos a las pantallas compensamos las deficiencias de una realidad que nos frustra constantemente, esto, además, renueva nuestras confianzas en el nuevo mundo virtual, donde podemos desechar sus objetos amenazantes como si se tratara de cualquier producto del mercado.

Para todo sujeto, la realidad supone la ininterrumpida búsqueda por el (re) encuentro con el objeto de deseo, si bien tal empresa no siempre trae consigo los mejores réditos y termina por frustrarnos por la falta originaria de dicho objeto, la realidad promete la posibilidad de encontrar su satisfacción en los objetos que cancelan parcial y momentáneamente la tensión pulsional en el interior de nuestro psiquismo. Según Freud, en los primeros meses de vida del sujeto, cuando su Yo apenas está constituyéndose - ese Yo que podríamos 1lamar primordial-divide el mundo en "objetos que son fuente de placer" -espejo de donde adviene el Ich-Lust- y "objetos que son fuente de displacer" -espacio que reúne el no-yo del sujeto. A los primeros, el sujeto quiere atraerlos hacia sí, primero, como fuente de satisfacción pulsional y segundo, para introyectarlos a la manera de piezas en que se edifica el devenir del Yo. A los segundos, los 
hostiles, el Yo los repele, procura arrojarlos fuera de sí pues ellos son origen de displacer y fuente de amenaza; a estos objetos el Yo de ningún modo querrá introyectarlos, por lo que en su lugar son alejados - ¿acaso también proyectados?- mediante la vía motriz de huida o retirada del mundo, o mediante su equivalente a nivel psíquico: la represión (verdrängung).

Lo que sucede en los entornos virtuales es que solo existen en tanto que realidad paradisiaca y no como una realidad capaz de provocar verdaderos estados de tensión, resistencia o amenaza; se procura que sus usuarios ocupen la mayor parte del tiempo consumiendo representaciones placenteras, con lo cual ejercen un poder sumamente adictivo, especialmente en los niños y adolescentes. Sus estados nos recuerdan a aquellos alcanzados por el consumo de sustancias psicoactivas en que un "sentimiento de nirvana" transporta vía regresión a los sujetos a la omnipotencia narcisista de la infancia, así como al abandono de la realidad mediante la ilusión apuntalada en el repertorio de fantasías inconscientes que yacen en su estructura.

Es justamente en esta su naturaleza acogedora, transformante y de hostilidad en potencia que lo virtual abarca también un aspecto positivo, pues, según algunos autores, sirve como "espacio de transición", donde los sujetos pueden trabajar sus conflictos de identidad que parecerían imposibles de atravesarlos en la realidad: "La virtualidad no debe ser una prisión. Puede ser la balsa, la escalera, el lugar de transición, la moratoria, que se descartan después de alcanzar una mayor libertad. No tenemos que rechazar la vida en la pantalla pero tampoco la tenemos que tratar como una vida alternativa" (Turkle, 1995: 231). Sin embargo, hay que tener cuidado, pues pensar los espacios virtuales como lugares de transición o como vía para la reincorporación del sujeto al seno de lo social, solo es uno de los aspectos de estos mundos, el cual no debe ser desestimado, pero nuestro examen expone el peligro de sobreestimarlo.

\section{El cuerpo: reconstrucciones en lo virtual}

Lo virtual como proceso de heterogénesis -volverse otro- reinventa el cuerpo, la anatomía humana y acaso hasta a la misma especie. En lo real existen intervenciones que se realizan a nivel del "soma": body building, cirugía 
estética, prótesis, implantación de órganos, etc., toda esta variedad de técnicas constituyen el medio por el cual el cuerpo humano sucumbe a este proceso de transformación de la imagen, el cual, la más de las veces, atiende al rigor de los cánones de belleza -ideal del Yo- tal como es concebida en nuestros días. Sin embargo, existe otra herramienta más accesible y menos riesgosa engendrada en los laboratorios de la ciencia digital: la heterogénesis virtual. Por este camino no solo podemos recomponer uno u otro rasgo de imperfección del cuerpo, sino que incluso es posible alcanzar verdaderas mutaciones de la anatomía humana nunca antes concebidas y hasta hoy imposibles mediante una cirugía estética. Lo mejor de todo es que si dichas transformaciones no nos satisfacen inmediatamente podemos fabricar un nuevo Yo digital, tan fácil como tomar una prenda de vestir.

En este apartado trabajaremos sobre las consecuencias psíquicas que las trasformaciones del cuerpo traen consigo, sin que la mayoría de sus usuarios reparen en ellas. El cambio de sexo virtual o transexualismo virtual, cyborgs y demás tópicos serán tomados en cuenta a continuación. Además -y quizá sea lo más importante-, abriremos el camino hacia una nueva problemática: la ética en lo virtual: ¿qué legislaciones existen en el caso de violencia sexual por internet o cuando un niño, haciéndose pasar por un mayor de edad, es requerido sexualmente por un adulto pedófilo?, ¿podemos hablar de infidelidad en lo virtual? Así pues analizaremos lo que una heterogénesis de lo humano implica tanto en lo psicológico como en lo moral, ético y legal. "La virtualización del cuerpo no es, por tanto, una desencarnación sino una reinvención, una rencarnación, una multiplicación, una vectorización, una heterogénesis de lo humano" (Lévy, 1999: 32).

Entendemos a la virtualización del cuerpo como un proceso de heterogénesis de la imagen primordial asumida en el espejo por un sujeto, en donde, por lo demás, el cuerpo de uno -el Yo-corporal, el Yo-placer-, el cuerpo íntimo y privado, marcado por la subjetividad de los límites de quien encarna, pasa a ser el cuerpo del otro y para el otro, dicho de otra manera: sacrifica su unidad yoica en virtud de reanimarse en las infinitas formas que emanan del "hipercuerpo".

Este movimiento implica, por una parte, la alienación del hombre respecto de sí mismo -el Yo como imagen especular-y de su inscripción simbólica en lo colectivo de un corpus humano: su especie; y por otra parte, implica la caída 
en los confines multidimensionales del hipercuerpo, del "otro" de la heterogénesis, cuyos patrones - en la configuración de su advenimiento- están caracterizados por la incapacidad de asumir cualquier forma única.

El hipercuerpo, el cuerpo universal que conforma lo humano, es un coloso imaginario no regido por principios naturales que contiene en su organismo descentralizado todos los órganos en que pervive lo que es de naturaleza humana, pero también los medios de su transfiguración. Este se manifiesta, por ejemplo, en los bancos de esperma, las unidades de transfusión sanguínea o de donación de órganos, mercados de prótesis, etc. y tiene su alcance más revolucionario en los implantes cibernéticos. Por lo demás, ya que su constitución es la de la comercialización de sus órganos, este es subordinado a las políticas de mercado del intercambio de los productos, a saber, el mercado neoliberal. Este es el orden ideológico a que atiende el hipercuerpo, y lo virtual es una de las expresiones de su existencia que se orienta según su deseo, es decir, la transformación de lo humano vía la comercialización de lo que lo constituye: sus órganos.

Cada cuerpo individual se convierte en parte receptora de un inmenso hipercuerpo híbrido y mundializado. El hipercuerpo de la humanidad, haciéndose eco de la hipercorteza que empuja sus axones a través de las redes digitales del planeta, extiende sus tejidos quiméricos entre las epidermis, entre las especies, más allá de las fronteras y los océanos, de una orilla a la otra del río de la vida (Lévy, 1999: 30).

Revolución de la carne, orden inacabado de transformaciones del cuerpo en pura potencia, incapaz de alcanzar realmente lo ideal. El límite del cuerpo es en lo virtual, lo difuso, de contornos inasibles, en sus múltiples formas solo se puede estar seguro su amorfismo. Una figura neutra -ne-autre del francés-, en cambio constante, sin piel, andrógino... no hay nada que lo inscriba en el marco de las identificaciones del género, la raza o la cultura.

Un problema de diferencias -el extranjero- y de semejantes -el prójimo-: desmentir la diferencia es en lo virtual asumir la indiferencia y la intolerancia al otro. Todo lo que vemos aquí es apariencia, intangible ilusión que sirve a la "retirada del mundo", pues en potencia existe un reino no marcado por la diferencia ni por la interdicción del deseo o la amenaza de castración que deriva de la ley paterna en el campo de la realidad. Lo virtual es el estanque fatal en que 
se contempla Narciso, quien cautivado en el fulgor de su imagen resiste todo reconocimiento por la diferencia que le viene en el encuentro con sus semejantes. Podríamos aventurar incluso que mediante la perenne contemplación de sí en esta imagen virtual, sucumbe el sujeto al mortal reino de lo imaginario, lugar de resguardo de la angustia provocada por el reconocimiento de la diferencia en el otro. Así pues, lo virtual sirve de anteojos a la desmentida.

En la vida real uno no toma decisiones respecto al tipo de cuerpo en desearía encarnar pues estamos todos sometidos a los azares con que la naturaleza ordena los códigos genéticos propios a la biología humana. El día de hoy, en cambio, se nos propone tomar decisiones sobre nuestra propia configuración genética, la ciencia, la robótica, lo virtual... la especie misma en el proceso de heterogénesis. En este sentido, lo virtual lleva la ventaja de que las posibilidades de invención son verdaderamente ilimitadas, todos los atributos son asumibles a nuestra nueva forma, solo basta elegir el cambio. Bien podríamos no contentarnos con mejorar nuestros rasgos estéticos, pues si quisiésemos, las transfiguraciones zoo-antropomórficas son posibles, así como cualquier mutación que reinvente la realidad del cuerpo en nuevos trazos de geometría; la consigna es invertir el orden de la naturaleza respecto de nuestro propia condición, sexo, raza, edad, etc. y construirnos en posición inversa a la de la realidad. La única limitación, se dice, está en el deseo y la imaginación.

Se prefieren las virtualizaciones del cuerpo debido a la facilidad, rapidez, versatilidad y los peligros aparentemente inexistentes con que se operan los cambios en este laboratorio de ficciones. Se cree que las mutaciones virtuales carecen del riesgo que todo intento de modificación del cuerpo en lo real representa; por ejemplo, la gente puede perder la vida en una cirugía estética, cosa que no sucede en lo virtual, pues allí nuestros cuerpos no tienen nada que "sufrir" cuando elegimos re-modelarlos. "La virtualización del cuerpo que experimentamos hoy, al igual que la de las informaciones, los conocimientos, la economía y la sociedad, es una nueva etapa en la aventura de la autocreación que perpetúa a nuestra especie" (Lévy, 1999: 27).

De este modo, el ser humano tiene por primera vez en sus manos la capacidad de elegir por sobre los dictámenes de la naturaleza a la que otrora habría estado determinado. Es el máximo exponente en la noción de libertad humana: la revolución digital. Pero no debemos olvidarnos que estas libertades a lo que 
verdaderamente están destinadas es a la huida del mundo, son un nuevo mecanismo a la desmentida de la realidad y su conato de desdén: la certeza de envejecer, morir y ver en ello palidecer nuestra juventud, la condena de enfermar, fracasar y todas nuestras insignificancias y diferencias, que -tras el exilio de lo real- encuentran en el reino de lo imaginario la tierra del "superhombre".

Libertad de la carne que bien podriría pagar el precio de Narciso por su exceso de amor por la imagen ideal, asumida en tan fatal espejo, el espejo que impide la subjetivación acaecida en el intercambio simbólico con el otro. Estas libertades virtuales equivalen justamente a la liberación de las ataduras para con el otro, de los vasallajes del cuerpo y el mundo exterior.

\section{Cyborgs: el superhombre}

Alejados por un momento de las pantallas, en el campo en que se interesan los ingenieros en biotecnología, existe la infatigable tarea por perfeccionar el diseño humano de los azares que la evolución nos heredó hasta ahora. Se trata del humano en su estado de evolución biotecnológica más elevada, aquel que supera todas las deficiencias de su actual condición genética -su proclividad a enfermar, envejecer y morir. Nada más revolucionario como antinatural que esta respuesta a los avatares que condicionan la vida a su término: los cyborgs serían la respuesta a este imperativo por fabricar al ser humano ideal, y uno de sus caminos -aunque no el único- es esta suerte de simbiosis hombre/máquina, coalescencia de circuitos electrónicos y tejido humano.

Luis Racionero sugiere que el camino del futuro es conectar pasarelas electrónicas directamente a nuestras redes neuronales biológicas mediante algún tipo de ingeniería biónica que ya está en desarrollo (Kerckhove, 1999: 75).

Neil Harbisson fue, en 1982, el primer cyborg reconocido en el mundo. Este hombre padecía de acromatopsia, una condición visual que desde su nacimiento le hacía ver el mundo en blanco y negro. Es por esto que, a sus veinte años, crea por sí mismo y se instala un mecanismo cibernético llamado eyeborg en su corteza cerebral, para poder "escuchar los colores". 
En la actualidad, varias son las personas que se han instalado distintos mecanismos electrónicos en diferentes áreas de su sistema nervioso con la finalidad de compensar deficiencias congénitas o mejorar el rendimiento de su funcionamiento fisiológico. Lo que fue alguna vez ficción es hoy motivo de ciencia y construcción del futuro, reinvención de la especie y los constructos mentales en que esta fue gestada hasta el día de hoy.

Por ello, ¿en lo social se auspicia un nuevo fenómeno de segregación: el cyborg y a sus pies todos los mortales? ¿Cómo filósofos, sociólogos, antropólogos, psicólogos, psicoanalistas y demás académicos comprometidos debemos responder a los cambios que vivimos hoy, cuando el ser humano parece arrebatarle todo su poder a las leyes de la naturaleza? ¿Qué respuestas tenemos para las generaciones más jóvenes que viven en carne propia la fuerza del impacto de metamorfosis tan feroces que prometen subvertir el orden del mundo?

\section{Transexualismo virtual: cybersex}

Algunos hombres interpretan personajes femeninos para tener netsex (sexo en la red) con hombres. Y en el "síndrome de falsa lesbiana" hay hombres que adoptan personajes femeninos electrónicos para tener netsex con mujeres (Turkle, 1995: 282).

Realidad virtual, espacio imaginario en que la omnipotencia del deseo recobra toda su fuerza alucinante tras derogar la ley fundante en que se sostiene el principio de realidad. Espacio fronterizo en que el deseo vuela libre de los pesos de la carne siguiendo la guía imaginaria del principio de placer. El objeto de deseo -aquel que cancela parcialmente la tensión y brinda satisfacción en el interior del aparato psíquico- tras un juego de espejismos, es ceñido por un halo imaginario cuyo resplandor seduce mortíferamente. Hemos creado el universo donde las personas ocupan el lugar divino del creador, siendo así que la ley fundante del juego de relaciones del sistema que lo regía, constituye ahora una mera variable en la lógica de su programación binaria. Arbitrio humano del juego con la ley y sus virtuales pero no menos efectivas consecuencias. 
Es mediante estos procesos de digitalización de la imagen que no solo podemos dejar los registros de la carne a un lado, sino que además podemos asumir la neutral faceta en el anonimato en que somos "nadie y todos a la vez".

Cabe preguntarnos entonces ¿qué consecuencias psíquicas operan en una transformación digital del sexo cuando con Freud sabemos lo irrevocable de las consecuencias psíquicas que la diferencia anatómica de los sexos comporta? La diferencia anatómica de los sexos es el fundamento de nuestro ser en tanto masculino o femenino, o en tanto existe un más o un menos en la ecuación de la "sexuación". A la diferencia anatómica de los sexos, hasta el día, ninguno ha escapado, es la condición previa a toda construcción psíquica en que se sostiene el andamiaje de discursos donde opera la diferencia sexual. Posicionarse de uno u otro lado en relación al significante de la falta (o) es, por lo demás, reconocimiento de la diferencia sexual, que en último análisis implica la división estructural como fundamento de los sujetos humanos.

Ahora bien, cuando hablamos de un cambio de sexo en lo virtual, el mecanismo en juego es el de la "desmentida" -la imagen como substituto de una falta que en el campo de la realidad es percibida como intolerable. Tengamos en cuenta que operamos dicho cambio a nivel virtual, como una imagen que, proyectada en la pantalla de un monitor, es capaz de provocar -aun sin su sostén en lo real- procesos de identificación dirigidas a la imagen de un alter-digital asumida, a partir de allí, como un reflejo de sí mismo. Cabe añadir que dicho reflejo constituye la representación del ideal de la persona; de cómo esta desearía verse y lucir ante los demás, proyección que constituye el modelo al que ajustar el cuerpo. Aun así, dicha transformación computarizada acarrea cambios significativos en el orden del discurso que gira en torno al nuevo semblante imaginariamente adquirido. Es así que se habla en nombre de... semblante de $\mathrm{X}$, no análogo al ser que encarna, un ser digital que asume la palabra del sexo que le está, por naturaleza, negado.

Esta reivindicación virtual de las propiedades sexuales del ser humano redistribuye en un nuevo orden el emplazamiento de los significantes que se inscribían en la imagen-corporal del ser en tanto masculino o femenino. Hecho que constituye una de sus consecuencias psíquicas más relevantes pues es aquí dónde evidenciamos el modo en que una heterogénesis del sexo en lo virtual inaugura, en los procesos de identificación en que se erige el Yo, atributos in- 
éditos de identidad y la apropiación a nivel del discurso de un nuevo significante sexual.

Pero ¿qué consistencia puede tener el discurso de un hombre que un día se hace pasar por una mujer y al día siguiente por un niño o más tarde por la misma Afrodita? Respondemos que ninguna; constituye por el contrario la irrupción violenta de un nuevo significante, el Yo-digital, en la identificación realizada sobre la anatomía sexual. Y es esto lo que preocupa a la hora de pensar acerca de la construcción de la identidad libre de conflictos pues, para que esta tenga lugar, es necesario fundarla sobre bases de identificaciones sólidas y continuas en el tiempo originadas a partir de otro, de la alteridad el cual es a su vez capaz de sostener su propia continuidad y la coherencia de un discurso asumido a partir de la imagen que encarna su anatomía sexual.

Lo real representa la única materia en cuya solidez podemos confiar no se desmoronará con los constates embates de la experiencia humana; por el contrario la cualidad efímera y desechable de un Yo-digtal solo puede traer como consecuencia trastornos de identidad que bien podrían desembocar en patologías tales como la despersonalización o la desrealización de los usuarios más fervientes a estas tecnologías. La diferencia anatómica de los sexos es la única que permite a los sujetos construir su identidad en los márgenes de una realidad corporal, cuya estabilidad asienta las bases para devenir del Yo. Pero sobre todo, posibilita la construcción de una identidad corporal que sirve de amarre a la pertenencia del sujeto a una especie, un género y a una cultura. Esto significa erigirse como sujetos.

El problema del transexualismo no lo estudiaremos aquí a profundidad pues rebasa los límites de la materia que está aquí en juego, sin embargo, nos interesa decir que la cuestión se plantea como una especie de negación o rechazo hacia la percepción de la imagen del propio cuerpo, imagen que en lugar de generar un proceso de identificación provoca más bien el efecto contrario, es decir, su repudio. De tal modo que la imagen-corporal -desde la cual se erige el Yo-quiere ser "expelida" en lugar de "atraída" hacia sí, como si se tratara de un alma femenina cautiva en un cuerpo masculino, realidad que lo desespera y angustia hasta el punto que su psiquismo opera divorcio -a manera de denegación- entre esta y su fantasía de convertirse en una mujer. 


\section{La responsabilidad en lo virtual}

Lo interesante de escondernos tras las máscaras de un Yo-digital es que con ello además eludimos las responsabilidades que la vida real trae para cada acción que realizamos en ella. En el mundo virtual, el tornarse otro implica por lo demás enajenarse de la propia ley moral que regula deseo y goce entre los seres humanos; fuera de la ley las oportunidades de gozar se extienden hasta los confines de las tiranías de los deseos más distorsionados. El anonimato o seudónimo que representa a los personajes virtuales, eximen a sus usuarios de cualquier represalia que una cultura determinada pudiera tomar ante cualquier acto delictivo ocasionado en la vida real. Nadie puede castigar a quien se oculta tras los innumerables disfraces de un Yo siempre en transformación; sin un ser que encarne un nombre (onoma) no hay delito que reclame su justa sanción, tan solo el silencio fugitivo de un monigote virtual que burla la ley. Más aún si, recordémoslo, en lo virtual la ley no es otra cosa que una variable en el juego algorítmico al arbitrio de su programador digital.

El sexo virtual o cybersex, es una de las modalidades de interacción humana más polémicas en cuanto a la responsabilidad moral que cada usuario debe asumir con su Yo-digital. ¿A quién responder, quién lo hace y bajo qué acusaciones? Por ejemplo, ¿qué hay acerca de los actos de infidelidad vía internet (cybersex) o la violencia sexual como la pedofilia on-line, por ejemplo?

El sexo virtual plantea la pregunta de qué hay en el centro del sexo y de la fidelidad. ¿Es la acción física? ¿Es el sentimiento de una intimidad emocional con otra persona que no es nuestro compañero o compañera fundamental? ¿La infidelidad está en la cabeza o en el cuerpo? ¿Está en el deseo o en la acción? ¿Qué constituye la violación de la confianza? Y ¿hasta qué punto y de qué maneras tiene que importar quién sea el compañero o compañera sexual virtual en el mundo real? El hecho de que el cuerpo físico se ha dejado fuera de la situación hace que estas cuestiones sean más sutiles y a la vez más complicadas de resolver que lo eran antes (Turkle, 1995: 283).

El llamado acto de contrición cristiano ruega perdón en: "pensamiento, palabra, obra y omisión". Por este camino podría pensarse que un delito de pensamiento constituye "en virtud" un crimen per se sin que exista ningún acto 
que ejecute tal pensamiento en la realidad. Estas cuestiones son sumamente difíciles de responder y requieren de un examen bastante riguroso de lo que significa la necesidad de una ley reguladora en un espacio intermedio como el de lo virtual, ámbito de todas las libertades idílicas y de la flexibilización de la ley natural más inexorable, en tanto que es un mundo no asentado en lo real, mundo versátil, ilusión de un espacio sin gravedad ni tiempo.

Le pregunto si la actividad sexual en conexión le ha cambiado las cosas. Dice que ha aprendido más de los "chicos mayores" con los que no ha tenido la posibilidad de salir. Le pregunto si alguna vez se le ha insinuado alguien que ella creyera que era un adulto. Dice que no, pero entonces añade: "bueno, ahora, a veces me conecto y digo que tengo dieciocho años, así que si lo hago más puede que suceda". Le pregunto si esto le preocupa. Deja muy claro que se siente segura porque siempre se puede “desconectar” (Turkle, 1995: 286).

Recordemos con Freud que la concepción de la sexualidad en la niñez y en la adolescencia no es en modo alguno la misma que la de los adultos. En Tres ensayos sobre teoría sexual se entiende que la representación que el niño hace su sexualidad, así como el modo en que concibe el medio por el que "los niños vienen al mundo", consiste en un juego de fantasías que apenas tiene comparación con lo que los adultos saben al respecto. Por ello, un niño puede quedar verdaderamente traumatizado ante los reclamos eróticos con que un mayor quisiera abusar de su sexualidad, aun en lo virtual, pues aquí se trata de una incitación de palabra e imagen con plena capacidad de causar efectos. Hecho de profunda relevancia a la hora de fundar su futura constitución psíquica, en donde las secuelas de dicho acto podrían afectarlo gravemente.

Es por esto que debemos estar prevenidos. Nuestra responsabilidad es una respuesta a todo acto que de nosotros provenga, sin importar el contexto en que este tenga lugar, sea que este se ubique en el mundo real o en un ámbito puramente virtual, lo que verdaderamente importa es la capacidad que sus impactos tienen para provocar efectos en la dimensión psíquica de los sujetos. Nadie debe eximirse de responder por sus actos, ni en lo virtual ni en ningún otro lugar. La base de todo vínculo social está en los límites que se trazan frente al otro, como un código de conducta consentido para el común acuerdo y amparo de las personas. De lo contrario, al rasgarse esos límites reguladores 
del deseo, seguiremos el carril más deshumanizante de especie. Romper estos acuerdos equivale al destierro de la sociedad, cuyo contrato funda lo humano, única fuente de donde florecen las identificaciones por las que devenimos seres de palabra. Lo otro significaría exacerbar las individualidades con su consecuente ruptura del lazo social, origen de la enajenación y deshumanización de las personas.

\section{La realidad a prueba de lo virtual: (re)construcciones}

Nos interesa ahora comparar los supuestos en que se sostiene la noción de realidad en el psicoanálisis freudiano con aquella que la teoría de las comunicaciones y la informática proponen respecto a su equivalente virtual: proceso de virtualización de la realidad. De este modo perfilaremos la diferenciación que el concepto de realidad hace para los distintos campos teóricos en juego. Alcanzado este propósito, habremos de conducirnos hacia una nueva problemática, a saber, qué sucede con la construcción psíquica del fenómeno sensorial llamado "realidad" cuando esta se ve sometida a los incesantes impactos de lo virtual. Por esta línea hemos de resolver: 1) ¿es la realidad una construcción a la vez, cultural y subjetiva del hombre, susceptible de alteraciones y transformaciones?, y 2) ¿es la realidad una formación a priori y ajena al ser humano, incognoscible e inasible en su fundamento, por tanto no susceptible de cambios sustanciales? Solo las respuestas a estas preguntas prepararán el camino a futuros esclarecimientos respecto a los peligros que un contacto desmedido con estas tecnologías puede provocar en los sujetos en estadios de desarrollo psíquico aún tempranos.

Lo inconsciente es lo psíquico verdaderamente real, nos es tan desconocido en su naturaleza interna como lo real del mundo exterior, y nos es dado por los datos de la conciencia de manera tan incompleta como lo es el mundo exterior por las indicaciones de nuestros órganos sensoriales (Freud, 1900: 600).

Esta anotación de Freud elucida la naturaleza de una realidad (el Umwelt) entendida como un conjunto de datos sensoriales registrados en el aparato psíquico con la legitimidad de un facsímil, pero no como lo real per se. Lo que 
del mundo real somos capaces de percibir gracias a nuestros órganos de los sentidos no corresponde sino a un pequeño fragmento de este, cuya magnitud no rebasa los estrechos límites de un ángulo de mirada, por tanto, es subjetivo. El propósito de recrear tal imagen psíquica de lo real tiene que ser el de sobrevivir a los avatares por la "supervivencia del más apto", apremios de la vida que desencadenan tensión psíquica como el hambre, el frío o la reproducción. En otras palabras, de lo real del mundo exterior no registramos más que una copia legitimada por el buen funcionamiento del sistema percepción, que la transcribe conforme al entorno en función de las necesidades propias de la biología humana; esta imagen sin embargo no deja de ser parcial y algo imprecisa, además de estar trastocada por la intervención de los procesos psíquicos al momento de imprimirla en nuestra mente.

Esta suerte de desnaturalización acaecida sobre lo real, inherente al proceso mismo de su captación en tanto que imagen-percepción, cuyas imágenes del mundo a las que en su reproducción psíquica llamamos "realidad", cumple un objetivo vital en la supervivencia humana. Si el aparato de percepción obrara de modo negligente al momento de imprimir la percepción-realidad en nuestras mentes, esto solo provocaría que los sujetos perecieran ante los pies de Ananké. Significa entonces que hemos de certificar la realidad abstraída por nuestros sentidos como una "realidad efectiva", es decir, una realidad a la vez eficaz y capaz de producir efectos. No siempre nuestros ojos nos engañan afirmaremos $\mathrm{y}$, sin embargo, cada dato de la realidad por ellos registrada es siempre la punta de un iceberg y jamás su totalidad.

En ese largo y severo trajín que representa el devenir humano, también recogemos las piezas con las que construimos, además de nuestra identidad, su realidad. Todo comienza en el vientre materno, cuando indiferenciados de nuestras madres éramos incapaces de reconocer los objetos del mundo como entidades ajenas y separadas al Yo, puesto que este se hallaba (con)fundido en todas las cosas. De este modo, tanto para el pequeño feto como para el neonato, no hay diferencia entre el sí mismo, el mundo interior y los objetos de su entorno (mundo exterior), no existe ante él una imagen de la realidad que se sostenga diferenciada en los horizontes de su percepción. Es en esta época de la vida del niño en que Freud supone un primer estadio del aparato psíquico en que este se comportaba a la manera de un aparato "reflejo". Dicho aparato tiene un funcio- 
namiento por entero distinto al de un aparato psíquico en pleno desarrollo, y es solo a partir del deshacimiento a la compulsión por la alucinación del objeto de deseo -por ejemplo, el pecho materno-que le es posible al individuo trascender a la abstracción de un mundo objetual, con entidades en oposición al Yo del sujeto: esto es el "principio de realidad" freudiano.

Nada nos impide suponer un estado primitivo del aparato psíquico en que ese camino se transitaba realmente de esa manera, y por tanto el desear terminaba en un alucinar. Esta primera actividad psíquica apuntaba entonces a una identidad perceptiva, o sea, a repetir aquella percepción que está enlazada con la satisfacción de la necesidad (Freud, 1900: 557-558).

Dicho enlace psíquico entre la huella psíquica de una vivencia de satisfacción - de cuando el lactante recibía del seno materno, la percepción del objeto que aliviaba la tensión del hambre- y el "recuerdo" de dicha percepción, terminaba en una alucinación cada vez que el niño volvía a desear el alimento. Así, la identidad perceptiva no procuraba en modo alguno la satisfacción necesaria para suprimir el estado de tensión en el interior del aparato, entonces, el deseo era, en un primer momento, alucinar el objeto de deseo, estadio al que sobrevino un ulterior y definitivo desarrollo "más acorde a fines". Indica Freud en sus análisis que dicho desarrollo del primitivo aparato reflejo tuvo que producirse con el fin de representar las constelaciones de la realidad de tal manera que le fuera posible acceder a la satisfacción por el objeto de deseo y que fuera capaz de detener los montos de displacer sentido en su interior. "Se hace necesario detener la regresión completa de suerte que no vaya más allá de la imagen mnémica y desde esta pueda buscar otro camino que lleve, en definitiva, a establecer desde el mundo exterior la identidad [perceptiva] deseada" (Freud, 1900: 558-559). Esto es la "identidad de pensamiento". Para esto, sin embargo, una amarga experiencia vital tuvo que haber modificado esta primitiva actividad de pensamiento en otra, secundaria, más acorde a fines:

Investiguemos la contraparte de la vivencia primaria de satisfacción, la vivencia de terror frente a algo exterior. Supongamos que sobre el aparato primitivo actúa un estímulo perceptivo que es la fuente de una excitación dolorosa. Entonces sobrevendrán prolongadas y desordenadas exteriorizaciones motrices hasta que por una de ellas el aparato se sustraiga de la percepción y, al mismo tiempo, del 
dolor; y cada vez que reaparezca la percepción, ese movimiento se repetirá enseguida (algo así como un movimiento de huida), hasta que la percepción vuelva a desaparecer (Freud, 1900: 589).

Solo a partir del pleno desarrollo del aparato psíquico y no antes, el ser humano organiza los múltiples objetos del mundo exterior en constelaciones psíquicas ordenadas y continuas en el espacio y tiempo físicos. Este nuevo y mejor adaptado aparato ya no atiende a los imperativos de un principio de placer que lo conducía directamente desde la huella mnémica de la satisfacción hacia la alucinación del objeto de deseo, sino que ahora alcanza dicha satisfacción a través del principio de realidad que se constituye merced a las vivencias de satisfacción y dolor: "así se introdujo un nuevo principio en la actividad psíquica; ya no se representó lo que era agradable, sino lo que era real, aunque fuese desagradable" (Freud, 1911: 224).

Concluimos que la realidad es, en la teoría psicoanalítica, un fenómeno psíquico sensorial de la más alta complejidad, naciente de los proceso psíquicos más tempranos que tiene lugar en el sujeto para el momento en que este es impelido por la necesidad al encuentro con el otro (prójimo) concebido como objeto de satisfacción pulsional o como objeto hostil del que hay que librarse para resguardar su propia supervivencia.

Esta realidad es de naturaleza neurofisiológica, un trasunto sensorial por medio del cual los códigos del mundo exterior se vuelven inteligibles para la mente humana, en otras palabras, es una representación lo más legítima posible de lo real del mundo incognoscible es su naturaleza interna. Es, entonces, una realidad proclive de sufrir alteraciones, transformaciones y por supuesto también deformaciones debido a las bases fenomenológicas en que se construye en el interior de cada individuo y en correspondencia con el funcionamiento adecuado de un aparato psíquico que opera al modo de una pizarra mágica, es decir, como un conjunto de sistemas topológicamente ubicados cuyas experiencias dejan la huella (psíquica) de su paso por el mundo. 


\section{La realidad virtual en sus mecanismos de operación psíquica}

La realidad tal como nos aparece en los sistemas de simulación virtual es, ante todo, una realidad de síntesis, esto es, una realidad artificial fabricada por el hombre. Esta realidad se compone, en sus niveles de programación estructural, de un leguaje lógico-matemático al que se denomina código binario. El cifrado particular al que dan lugar las reglas algorítmicas de dicho sistema genera una combinación estricta de comandos que rigen la matriz operativa de un programa o software en el computador. Sin embargo, lo que aparece ante nuestros ojos no es su estructura lógico-simbólica compuesta por la organización algorítmica de unos y ceros, en su lugar vemos más bien un haz de estímulos sensoriales finamente coordinados entre sí para que nuestras vías nerviosas las reproduzcan como realidades tridimensionales en un tiempo y espacio que parecen reales. Por otro lado, las técnicas de representación virtual son esencialmente numéricas (digitales), a diferencia de las técnicas de transducción analógica como la fotografía o el teléfono tradicional, así, los sistemas numéricos permiten trascender lo real y esa es la razón de sus mayores alcances, pues si lo analizamos desde un enfoque psicológico, en esencia, sus producciones no están regidas por ninguna ley física que les sea absoluta, es decir, fundante. Son creaciones al arbitrio del hombre, manipulaciones simbólicas del lenguaje que le es propio.

Entendemos, entonces, que la realidad virtual sea pura ingeniería de la recreación, la cual engaña nuestros sistemas nerviosos con las múltiples ficciones que en nuestro sistema percepción es capaz de suscitar. Del mismo modo que sucede en el soñante cuando este se encuentra sumergido en las imágenes oníricas propias al proceso de dormir, un sistema de realidad virtual recrea sensaciones a las que los sujetos reaccionan en modo equivalente a que si encontrara dichas imágenes en el mundo exterior. En el sueño se manifiesta el fenómeno de la certeza por lo soñado a la manera de la identidad perceptiva, cada vez que la persona sueña, retorna - pues se trata del proceso de "regresión"- a ese estado primitivo del aparato en que "el desear, terminaba en un alucinar". Del mismo modo podríamos advertir que, sumergidos en un sistema de realidad virtual, lo que se produce en el aparato es análogo al proceso de la identidad perceptiva en donde el sujeto reencuentra el objeto de su deseo proyectado en los haces que se disparan a su retina y crean el mismo fenómeno que se manifiesta en lo 
soñado: el de la certeza. Es a precio de burlar la conciencia y el principio de realidad que lo virtual se disfraza de realidad y se la asume, a nivel del sistema percepción, como tal.

Un fenómeno en apariencia tan sencillo como es el del sueño es capaz de ilustrar el inmenso poder del que están revestidas las imágenes a nivel psíquico. Basta que una de ellas aparezca como representación, placentera o displacentera, en nuestra conciencia -o en lo inconsciente- para que de ahí se desencadene toda una atmósfera de afectos ligadas a ellas. Además, dicho poder de las imágenes ha sido ilustrado a lo largo de la historia misma de la humanidad, a saber, en el arte y sobre todo en la pintura. Como bien nos enseña E. H. Gombrich, en los pueblos primitivos como los Egipcios, Griegos o Mayas existió la mágica creencia en el poder de las imágenes, en el que se creía trasuntaba el espíritu de las cosas. Así,

Las imágenes están hechas para proteger contra otras fuerzas que son, en su concepto, tan reales como las de la naturaleza. Pinturas y estatuas son -en otras palabras- empleadas con fines mágicos [...]. En ocasiones los pueblos primitivos aún dudan acerca de lo que es real y lo que es una pintura. En una ocasión, un artista europeo al dibujar sus animales, alarmó a los nativos: "si usted se los lleva consigo, ¿cómo viviremos nosotros?” (Gombrich, 1997: 40).

Desde los albores de la civilización el arte de representar por medio de imágenes ha acompañado a la humanidad sirviéndole de medio para la expresión de sus temores y devociones divinas, a la vez que ha ido modelando el pensamiento colectivo en el seno de la cultura en que han sido gestadas como iconos de idolatría universal. Hoy en día, la llamada revolución digital ha dotado al arte del diseño gráfico la destreza para representar los objetos de la naturaleza de un modo que ha rebasado con creces todo lo que hasta entonces se había logrado en siglos anteriores. El umbral de esta revolución marca la entrada en una nueva dimensión para la representación del mundo pues esta ya no se conforma con la representación fiel de la naturaleza en que tanto afanaban los artistas del Quattrocento y del alto renacimiento, al parecer su fin consiste en aventurarse a un más allá del todo limite sugerido como regla natural. Algo que, por supuesto, sugiere una revuelta de la aprehensión del mundo a nivel psíquico. 
La realidad de lo virtual no funciona bajo los supuestos físicos de un tiempo-espacio, atributos constituyentes de la realidad en la esfera terrestre; de tal modo podríamos sostener que lo virtual sirve justamente al deshacimiento psíquico- de la realidad efectiva. Representa su pérdida la "desmentida", un intento de fuga y de liberación a las ataduras que nos imponen los apremios de la de vida. Su reloj designa el tiempo de comer, de amar e incluso el de morir, variables todas con las cuales, en un sistema de programación virtual, se pueden jugar. Los procesos de simulación virtual son entonces una desestimación del mundo natural y sus leyes, y funcionan a la manera de un mecanismo muy particular: la desmentida. Es así que encontramos en los placeres de lo imaginario (lo virtual) el nuevo opio de los pueblos como el medio perfecto para rehuir a la más dolorosa de la realidades, el de haber encarnado en seres mortales.

Lo virtual "invierte" el sentido de realidad instituido a partir del pleno desarrollo del aparato psíquico mediante la fabricación de una realidad de síntesis, cuyos modelos imaginarios inauguran un nuevo plano de la realidad a través del cual entender las viejas coordenadas espaciales en que la construíamos sobre el campo de la realidad. Una tal reconstrucción genera además una organización diversa de sentidos articulados a los significantes virtuales operantes en función de una nueva cosmovisión apta para la comprensión del mundo. Este carácter de una realidad sin apoyatura, cuya propiedad más característica es la velocidad de sus movimientos orientada hacia una heterogénesis, genera cambios tan radicales como inasimilables en el psiquismo, lo cual constituye la causa primera de su nocividad sobre todo en edades tempranas, cuando los procesos de identificación del sujeto empiezan a germinar y a tomar forma definitiva, a saber, en la infancia por un lado y en la adolescencia por el otro.

Para Kant, el espacio es una representación necesaria a priori que fundamenta todas las intuiciones externas. Según él, la inexistencia del espacio es inconcebible. E incluso el espacio se convierte, desde ese punto de vista, en una condición de posibilidad de los fenómenos, como es la condición subjetiva de nuestra sensibilidad. El espacio no representa una propiedad de las cosas en sí ni estas en su relación entre sí. Es la condición previa de la relación del sujeto a las cosas (Quéau, 1995: 22). 
Si bien la realidad virtual simula las propiedades de nuestro espacio, esta no constituye un lugar real, no nos asegura ni una base ni una posición. "Esta base y esta posición son condiciones de existencia y de conciencia. La posición (en el espacio real) no es un mero atributo de la conciencia, sino una condición previa a ella" (Quéau, 1995: 25), por ello hemos de distinguir los procesos psíquicos en los que nos sumergimos bajo el display de una realidad virtual, donde tenemos la sensación -aun corporal- de asentarnos en el suelo de un espacio definido, sin embargo, dicho asentamiento no tiene más lugar en lo real que el de un hálito, un hálito estupefaciente en el que sucumben conciencia y examen de realidad, ambos a la vez, los cuales, según explica Freud, están íntimamente ligados al desarrollo de los sentidos. Es una mera sensación de (bien)estar en que la fantasía se vuelve experimentable gracias a las reacciones corporales que sus imágenes desatan a nivel psicofisiológico; una corriente de estímulos virtuales capaces de controlar los niveles de angustia y de placer de sus usuarios; réplica digital de la experiencia del estar-ahí en el mundo.

Cuando a la luz de las nuevas técnicas de representación virtual nos encontramos con universos de imágenes creadas por el hombre, nos agrada ese sentimiento de que las leyes que comandan el mundo real no poseen allí verdadero efecto. Por ejemplo, lo fascinante de involucrarse en un juego de guerra virtual es que el incremento de los niveles de adrenalina en el cuerpo es real, pero el disparo que tu rival asesta en tu pecho solo produce desazón. Es así como la representación de la muerte no solo pierde efecto, pues ya no se la teme como antes, sino que lo virtual subvierte su función -que estaba destinada a marcar el término de la vida- al transformarla en el origen de una nueva partida.

Otro de modelo donde se juega con la ley es cuando el hombre se vuelve "creador" de todos sus habitantes y criaturas. Lo que allí vemos es el reflejo del rostro del hombre convertido en un dios: facultado para la creación de universos nuevos bajo sus propias leyes. "Aujourd'hui, avec le numérique, elles visent à satisfaire ses désirs les plus fous, par exemple être présent à plusieurs endroits au même temps ou communiquer avec le genre humain dans son entier. Des désir qui passaient jusque-là pour être réservés à Dieu"' (Stiegler y Tisseron, 2009: 45).

5 "El día de hoy, con lo digital, apuntan a satisfacer sus deseos más locos, por ejemplo, estar presentes en 
Sumergidos en mundos imposibles donde nos vemos volar a lomos de dragón nos erguimos victoriosos ante los imperativos de la realidad y sus apremios. Esta experiencia nos procura la sensación de haber alcanzado, por este camino, el máximo de los ideales de grandeza en que la humanidad en siglos pasados solo soñó. El hombre ha creado a Dios a su imagen y semejanza, como decía Freud en la Psicopatología de la vida cotidiana. Hoy en día hemos avanzado hasta tal punto que la idea de modelar al hombre hacia el ideal de su deificación no parece tan disparatada, sino virtualmente posible.

Vivimos una época en que los alcances tecnocientíficos en telecomunicaciones, inteligencia artificial, genética, física, etc. han provisto a la humanidad de una capacidad tal que en el pasado solo se le habría podido atribuir a un ser sobrenatural. Hoy, con su arsenal de artefactos, hasta el Olimpo se sacudiría de asombro y horror ante el poder de nuestra especie. Algo que no es de por sí un hecho feliz y que reclama lucidez y reflexión. La heterogénesis de lo virtual ya auspicia la trasformación radical no solo del ser humano en su singularidad, sino de la sociedad y las estructuras que fundan sus interrelaciones, y de la especie misma.

\section{Lo virtual: riesgos de desestructuración psíquica}

A continuación evaluaremos los riesgos que las tecnologías de recreación virtual traen para sus usuarios. Dedicaremos especial atención al examen de los efectos psíquicos acaecidos tras el impacto de lo virtual en niños y adolescentes.

\section{De la virtualización de los vínculos humanos}

Nunca antes se había podido estar presente en varios lugares a la vez ni encarnar diversas personalidades en un solo Yo. Las tecnologías de telepresencia posibilitan esta facultad en que ubicuidad y despersonalización son posibles

varios lugares a la vez o comunicarse con el género humano en su totalidad. Deseos que hasta entonces estaban reservados para Dios" (traducción del autor). 
para sus usuarios de internet; haciendo uso de su Yo-digital son capaces de trasladarse de un rincón a otro del ciberespacio sin dificultades ni demoras. Por otro lado, sabemos que la despersonalización consiste en la alteración de la percepción o de la experiencia que hace un sujeto respecto de su propio cuerpo y de sus pensamientos como si estos le fueran ajenos. Podría pensarse como un estado de extrañamiento del Yo y de la realidad, en que el sujeto se torna espectador de sí mismo, estado de ensueño en el cual la realidad pierde toda referencia -toda localidad- y verosimilitud.

Ya con las tecnologías de telepresencia las distancias geográficas han dejado de representar un problema para la interacción humana, desde su aparición en el mercado, se piensa que el hombre, mientras tenga a su alcance cualquier dispositivo que posibilite el ejercicio de una telecomunicación, estará permanentemente "conectado" a la red en la que se sostiene toda una comunidad virtual. Hecho, por lo demás, problemático, al tratar la cuestión de la presencia en el mundo, de la existencia en cuanto estar-ahí ( $D a$-sein), pues conduce a nuevas reflexiones ontológicas en cuanto a lo que está en el centro de la existencia. ¿Dónde está ese ser-en-el-mundo cuando, sentados frente a la pantalla de nuestro monitor, nuestro Yo-digital se aventura en una excursión virtual a través de la selva amazónica, por ejemplo? ¿En dónde debemos colocar el acento ontológico, en el Yo que se encuentra sentado frente al ordenador o en el Yo-digital que se halla en un lugar fuera del mundo, cuyas coordenadas nada tienen que ver con puntos geográficos reales? ¿Si tal Yo-digital es una existencia en sí misma, es posible pensar que hayamos alcanzado un proceso tan particular de despersonalización en que no opera tal divorcio en el juego de múltiples voluntades desplegadas ante sí, sino que cada Yo-digital es una multiplicación y una reencarnación del propio Yo del sujeto, que es el titiritero que las comanda?

Hacemos bien en platear estas preguntas aunque no sea este el lugar en que podremos resolverlas. Por ahora interesémonos por comprender cómo la naturaleza de los vínculos humanos, sostenidos anteriormente -anterior a las telecomunicaciones- en lo real del contacto con el otro, son transformados bajo el lema de ese "perpetua conexión a la red", sin importar el momento ni el lu- 
gar: “avec ces technologies, nous sommes dans l'illusion de rester toujours en contact. On n'apprend plus à être seul" (Stiegler y Tisseron, 2009: 44). ${ }^{6}$

La ilusión de una conexión permanente, sin cortes, mitiga la primitiva angustia de abandono que es fuente de la mayoría de las desconfianzas en el mundo. La compañía virtual del otro virtual provee un sentimiento latente de seguridad psíquica -quizás valiéndose de nuestra labilidad por la sugestión-que resuelve el problema del aislamiento y la amenaza de enfrentarnos a un mundo por cuenta propia a condición de poseer uno de estos dispositivos en que opera la presencia virtual. Sin embargo, la base de la salud psíquica de todo individuo se halla en el establecimiento efectivo de un vínculo humano, sea este, las más de las veces, el del niño con su madre por ejemplo. El estar conectados a una red global en tiempo real, juega en nosotros con esta imaginaria posibilidad de no alejarse del otro, de mantenerlo siempre al lado de uno. No obstante resolver las distancias virtuales es un beneficio que no viene solo pues también supone la capacidad de hacer aparecer o desaparecer a nuestros acompañantes de red de un solo "botonazo".

Cuando las relaciones interpersonales se despliegan en el campo de la realidad, en ese tener frente a sí una mirada, una voz y un gesto que se comunican a la par que una palabra, sabemos -aunque no conscientemente- que la entrada en contexto de tales significantes lleva una caga libidinal del tan alta que no nos es posible deshacer el despliegue de esa conversación de modo tan instantáneo como supone el soplo de cierre de sesión virtual, con un clic. Un diálogo en vivo reclama invariablemente la responsabilidad que hay que asumir para con nuestra palabra y el nombre que responde por ella. El anonimato que muchas veces sirve de mascara en las redes virtuales elude toda responsabilidad tanto en acto como en palabra que un sujeto debe tener para con el otro.

"Les liens sont de plus en plus précarisés, et cela s'accompagne d'un état croissant d'insécurité psychique qui n'a rien à voir avec l'insécurité réelle"7 (Stiegler y Tisseron, 2009: 45-46). En las redes sociales tipo Facebook, nos damos cuenta de qué modo el vínculo al otro se fragiliza hasta tal punto que pasa a

6 “Con estas tecnologías, estamos en la ilusión de permanecer siempre en contacto. No se aprende más a estar solos" (traducción del autor).

7 "Los vínculos están cada vez más precarizados y eso se acompaña de un estado creciente de inseguridad psíquica que nada tiene que ver con la inseguridad real" (traducción del autor). 
considerarse como una mera suma de contactos. Lo que se prioriza allí no es la calidad del vínculo social, sino la cantidad de los que su perfil pueda dar cuenta a los curiosos. Este ejemplo muestra claramente la manera cómo la revolución digital ataca a uno de los rasgos más esenciales de la naturaleza humana: el de ser un animal social.

En nuestra época es muy común ver a las personas, más aún los adolescentes, aferrados a sus celulares hasta el punto de no poder separarse de ellos sin evocar angustia ante la pérdida por dicho aparato, que imaginariamente es el receptáculo de su seguridad social. Esto demuestra que la virtualización de los vínculos humanos erige una ilusión de contacto que a veces llega a los alcances de un panóptico, de una vigilia sin sosiego que infunde una vasta seguridad. Sin embargo, estar atrapados en una red mundial de ilusiones provoca que el momento en que la conexión se interrumpa, se despierte la angustia, se corte el cordón con que se sostenía la relación al otro lado de lo virtual. La ilusoria seguridad asumida por usuarios en conexión virtual tiene eficacia psíquica si y solo si la interfaz es operante, es decir, si esta sostiene la conexión a la red de modo permanente, por el contrario si la red se corta, y la conexión al otro es interrumpida con ello cae la seguridad del sujeto. Precaria seguridad que convierte condiciona al sujeto a la heteronomía, imposibilidad de asimilar la separación al otro.

Por el contrario, para servirnos de un ejemplo de vital importancia en la psicológica de los hombres, el vínculo que se establece entre un niño y su madre -el otro primordial- constituye el fundamento de lo que se conoce como "confianza básica". Aquella confianza que le permitirá al niño emprender futuras exploraciones al mundo sin temor al abandono es el amparo de una huella mnémica investida por los cuidados con que lo apuntaló, de una vez y por todas, durante sus primeros 18 meses de vida. Habiendo asumido una pérdida, la separación de la madre cada vez que esta no está cerca, el niño se hace de un recuerdo que lo fortalece a nivel inconsciente. En otras palabras, confianza básica podemos llamar a esa confianza -a ese continuo resguardo psicológico que no cae a pesar de la separación de la madre y su hijo- que, partiendo de la figura primaria de afecto, permite al sujeto fiarse no solo de ese otro que le provee de cuidados y salvaguarda su integridad física, sino que inaugura el camino para la confianza en sí mismo y en el prójimo. Esta seguridad establecida en lo efectivo de un vínculo establecido en relación al otro infunde una seguridad 
que no se socava sin importar el lugar ni la compañía en que se encuentre el sujeto, pues este ha ganado para siempre confianza en el mundo, vehículo para la verdadera autonomía.

\section{A través de las pantallas la televisión}

Otro de los graves problemas con los sistemas de proyección virtual, es que estos tienden a paralizar la actividad pensante y motora de los sujetos quienes son ubicados en esta relación a la máquina en una posición pasiva. En cuanto a lo que se proyecta en las pantallas no hay más que hacer que sentarse y mirar el despliegue de imágenes que se presentan ante sí. Tal proceso no reclama sino la presencia de nuestro cuerpo y el encanto de uno o, a veces, dos de nuestros sentidos: la vista y el oído; de modo que los demás sentidos son atrofiados, por un hipofuncionamiento del sistema nervioso que no le procura la estimulación necesaria para el desarrollo de las distintas zonas cerebrales a través del olfato, el gusto y sobre todo de la manipulación de objetos. Esto último bien podría traer como consecuencias graves trastornos de aprendizaje en estadios tempranos de madurez psíquica, pues la corteza cerebral no se desarrolla ni de manera conjunta -sinergia- ni en su conexión con las vías motoras.

En cuanto a la estimulación táctil, "il est très important de se servir de ses dix doigts pour développer l'appréhension des trois dimensions de l'espace"8 (Stiegler y Tisseron, 2009: 20). El retraso en el desarrollo psicomotor que esto desencadena, provoca en los más pequeños una serie de dificultades que se anudan unas con otras y cuyo primer eslabón bien lo pudiéramos encontrar en la incapacidad de estos sujetos de establecer ese preliminar contacto con los objetos del mundo. Un niño que no toma con sus manos sus juguetes, que no los manipula, que no se ve cautivado por sus formas y texturas o que incluso los desgarra, un niño que no se ensucia en sus exploraciones por el mundo, es un niño que seguramente no alcanzará a aprehender a tiempo las dimensiones espaciales de su entorno. Asimismo, un retraso psicomotor está ligado íntima-

8 "Es muy importante servirse de sus diez dedos para desarrollar la aprehensión de las tres dimensiones del espacio" (traducción del autor). 
mente con futuros problemas de aprendizaje pues, como sabemos, la aprehensión de los objetos del mundo constituye la bisagra para su ulterior abstracción, es decir, para representárselos psíquicamente aun en ausencia de dichos objetos en el campo de las percepciones, esto es, la posibilidad del conocimiento. Pues la sensación que los objetos traen a través de su manipulación deja en el psiquismo un trazo, una huella mnémica de su figura, que más tarde no solo servirá para la representación psíquica de los mismos -representación-cosa-, sino para acceder al lenguaje -representación-palabra. Como vemos, interrumpir el juego de los niños al colocarlos frente al televisor, interrumpe toda una cadena cognitiva de aprendizaje en la que todos los sentidos cooperan para la evolución del conocimiento: "son développement psychomoteur nécessite en effet que ses cinq sens soient toujours engagés ensemble"9 (Stiegler y Tisseron, 2009: 19). Al retirarnos del mundo en lo virtual, también es retirada la investidura psíquica del mundo objetual y por ende el impulso curioso - pulsión epistemofílica- por conocer este mundo también desaparecerá. La televisión, al igual que los computadores, celulares y iPod, paralizan toda iniciativa en este sentido, pues en lo virtual el mundo no necesita ser manipulado, por tanto, se pierde la capacidad de análisis - posteriormente también su síntesis- de las partes que integran una entidad cognoscible en el marco de la realidad.

Debemos pues tomar nuestras precauciones, especialmente con los más pequeños y en los adolescentes, dado que es en estas edades cuando la mente de los sujetos empieza a adquirir su forma estructural definitiva, por lo que cualquier impacto indebido (en este caso el de lo virtual), que sobrepase un cierto umbral, bien puede provocar graves rasgaduras en lo ulterior de su desarrollo psíquico. No solamente, como vimos, ocasionando problemas psicomotores, sino también problemas de aprendizaje ligados a la dispersión de la atención y su consecuente hiperactividad en el comportamiento "l'exposition précoce aux images animées augmente les risques d'hyperactivité et de trouble du déficit de l'attention"10 (Stiegler y Tisseron, 2009: 70). Sin embargo, un efecto todavía

9 "Su desarrollo psicomotor necesita, de hecho, que sus cinco sentidos estén siempre comprometidos en conjunto" (traducción del autor).

10 "La exposición precoz a las imágenes animadas aumenta los riesgos de hiperactividad y de trastornos del déficit de la atención" (traducción del autor). 
más grave con que lo virtual amenaza la mente humana se encuentra en la ruptura del circuito de identificaciones primarias del sujeto, esto es la alienación:

La télévision lorsqu'elle court-circuite ces structures fondamentales où se forme la psyché, atrophie le développement des capacités psychosociales de l'enfant -et fragilise, voir anéantit le processus primordial que Freud appelait l'identification primaire ${ }^{11}$ (Stiegler y Tisseron, 2009: 82).

El solipsismo al que nos conduce el contacto extremado con las pantallas se produce como efecto del aislamiento creciente en que se encuentran los sujetos al momento de la contemplación casi divina de sus ídolos televisados. Esto no solo representa la clausura de las habilidades psicomotoras - como vemos- sino también representa el entumecimiento de la actividad parlante de los sujetos. El contacto con la televisión genera un tipo de desplazamiento de la información que es unidireccional: nada más fútil que iniciar un intercambio de palabra así. La televisión es nadie, integra una no-relación. El carácter impersonal del no-otro de las pantallas es lo que cierra la dinámica de la comunicación con el prójimo (los padres del niño, por ejemplo), sobrevenida como consecuencia del apasionamiento exacerbado por una realidad de pantalla que "desmiente" el carácter displacentero que se halla en la realidad.

Si esto se da así, relegando a los más pequeños al olvido en las pantallas, estaremos impidiendo los procesos de identificación con sus figuras primarias y secundarias de afecto. En este acto, lo virtual transforma la autonomía en pura heteronomía, pérdida total de sus capacidades de juicio y acción individuales. No solo nos volvemos dependientes de esta relación unidireccional e imaginaria con un no-otro televisado, sino que la dinámica en juego que se establece entre los sujetos y la máquina provoca el aligeramiento de su facultad racional capacitada para análisis, discernimiento, conocimiento e innovación. Bajo este aspecto enajenamos al sujeto de sus relaciones interpersonales, lo aislamos y lo amordazamos. Habla, pensamiento y acto clausuran sus funciones en favor de un consumismo pasivo de imágenes estupefacientes. Es la raíz de una alie-

11 "La televisión cuando cortocircuita estas estructuras fundamentales donde se forma la psiquis, atrofia el desarrollo de las capacidades psicosociales del niño -y fragiliza, incluso aniquila, el proceso primordial que Freud llamaba identificación primaria" (traducción del autor). 
nación, de la pérdida del sentido de realidad, semejante a lo que ocurre en la psicosis. En esta "heteronomización" a que contribuyen los procesos de identificación virtuales figura una relación inexistente con un otro cuya falsa relación comporta la anulación de los procesos constituyentes de la identidad y de la construcción del sentido de realidad y "un enfant sans identification primaire est un psychotique en puissance"12 (Stiegler y Tisseron, 2009: 84).

He aquí, según mi criterio, el peligro más grave al que nos enfrenta lo virtual: llevar a los sujetos a un punto tal de solitud en que, aturdidos en ese océano de imágenes que los capturan y apartados de la realidad y sus objetos, afirman la verdad de dichas imágenes, cuya certeza una vez asumida es capaz de difuminar las fronteras que se trazan entre realidad y fantasía. "Avant l'âge du collège, il risque donc d'y confondre apparence et réalité, d'y croire n'importe quoi, ou d'y livrer son intimité sans se rendre compte des risques qu'il court"13 (Stiegler y Tisseron, 2009: 39). Lo virtual se convierte, entonces, en marca de referencia, y cuando volvemos a lo real, creemos que aplicar con naturalidad las mismas actitudes, métodos y despreocupaciones es lo común.

Nos resultará fácil olvidar el mundo real y refugiarnos en la flexible y eficaz comodidad en la que nos sumergen estas perfectas herramientas de idealización. Por un lado, son instrumentos de dominio de la complejidad, instrumentos para una mayor inteligibilidad $\mathrm{y}$, por otro, estas mismas herramientas presentan una propensión a fomentar formas latentes de ilusión e incluso de esquizofrenia. Cuanto más utilicemos la simulación como herramienta de escritura y de invención del mundo, más corremos el riesgo de confundir el mundo con las representaciones que nos hacemos de él. Cuanto más creamos dominar lo real, cuanto más pensemos dominar los medios de transformarlo, más nos veremos tentados a huir de él y a refugiarnos en el mullido mundo de ilusiones que nos hacemos sobre él (Quéau, 1995: 41-42).

Ante todo esto tan solo nos queda enfatizar la enmienda necesaria para una ética, para una legislación de lo virtual, de la necesidad de un control parental

12 "Un niño sin identificación primaria es un psicótico en potencia" (traducción del autor).

13 "Antes de la edad del colegio, se arriesga pues de confundir allí apariencia y realidad, de creer allí no importa en qué cosa, o de liberar allí su intimidad sin darse cuenta de los riesgos que se corre" (traducción del autor). 
que evite los peligros que el impacto desmedido de lo virtual puede ocasionar en niños y adolescentes.

De ningún modo ha sido nuestra intención desmerecer los alcances y ventajas que lo virtual trae a nuestra sociedad, sin embargo, nuestro trabajo se ha concentrado en los problemas que estas tecnologías acarrean porque, a falta de límites y regímenes sociales y familiares, el contacto con lo virtual puede salirse de los linderos y convertirse en ese nuevo opio para las dependencias del sujeto al mercado, que atrofia nuestras funciones psíquicas, condenándolas al aligeramiento cognitivo en que se sostiene esta relación a la máquina. Solo si somos capaces de mirar lo virtual en su diferencia con lo real podremos prevenir todo tipo de sufrimiento psíquico de allí desencadenado. Para esto es necesario que dentro de las familias existan padres dispuestos a invertir tiempo en actividades compartidas con sus hijos y sobre todo que se interesen por lo que ellos "tienen que decir". Muchas veces los niños son abandonados a las pantallas porque no existe quién se ocupe de ellos y así, solitarios, encuentran por el camino del principio de placer un no-otro imaginario que constituye, para ellos, el único soporte de identificación y la única compañía que los ampara con esa pseudoseguridad que infunde su presencia. Cuando hay padres que se comunican con sus hijos y establecen los límites que regulan el uso de las pantallas, es seguro que estos padres no solo educan seres humanos psíquicamente sanos y autónomos, sino que entregan a la sociedad personas más aptas, que contribuyen a los progresos de la cultura y la humanidad con los frutos de su pensamiento y producción activa.

\section{Bibliografía}

Freud, S.

2008 [1900] La interpretación de los sueños (Parte I). O. C. Tomo IV. Buenos Aires: Amorrortu.

Freud, S.

2008 [1900] La interpretación de los sueños (Parte II). O. C. Tomo V. Buenos Aires: Amorrortu. 
Freud, S.

2008 [1911] Formulaciones sobre los dos principios del acaecer psíquico. O. C. Tomo XII. Buenos Aires: Amorrortu.

Freud, S.

2008 [1915] Complemento metapsicológico a la doctrina de los sueños. O. C. Tomo XIX. Buenos Aires: Amorrortu.

Freud, S.

2008 [1915] Pulsiones y destinos de pulsión. O. C. Tomo XIV. Buenos Aires: Amorrortu.

Freud, S.

2008 [1923] Neurosis y psicosis. O. C. XIX. Tomo Buenos Aires: Amorrortu.

Freud, S.

2008 [1924] La pérdida de la realidad en la neurosis y la psicosis. O. C. Tomo XIX. Buenos Aires: Amorrortu.

Freud, S.

2008[1925] La negación. O. C. Tomo XIX. Buenos Aires: Amorrortu.

Gombrich, E.

1997 La historia del Arte. Londres: Phaidon.

Lacan, J.

1949 Estadio del espejo. Escritos I. Buenos Aires: Siglo XXI.

Laplanche, P. J.

1996 Diccionarios de psicoanálisis. Buenos Aires: Paidós.

Lévy, P.

1999 ¿Qué es lo virtual? Buenos Aires: Paidós.

Negroponte, N.

1995 Ser digital. Buenos Aires: Atlántida.

Quéau, P.

1995 Lo virtual. Buenos Aires: Paidós.

Stiegler, B. y Tisseron, S.

2009 Faut-il interdire les écrans aux enfants? Paris: Mordiscus.

Turkle, $\mathrm{S}$.

1995 La vida en la pantalla. Buenos Aires: Paidós.

Envío 27 de octubre/2013 - Aceptación 17 de diciembre/2013 